\title{
A dinâmica dos sistemas de produção, as estratégias de intensificação e o papel da tecnologia de mulch na economia familiar
}

Raul Batista de Figueiredo - Engenheiro agrônomo, pesquisador associado ao NEAF/CAP/UFPA

Thomas Hurtienne - Professor do Núcleo de Altos Estudos Amazônicos, da Universidade Federal do Pará. (NAEA-UFPA).

\section{Resumo}

A agricultura familiar do Cumaru, no Nordeste paraense, estabelecida por meio de assentamento espontâneo, é uma agricultura de formação dinâmica, originária do processo de desenvolvimento interno e da migração de indivíduos oriundos do Nordeste brasileiro. No intuito de avaliar o uso de tecnologias de não queima no desenvolvimento dos sistemas de produção, este estudo busca analisar a evolução dos estabelecimentos familiares do Cumaru, suas estratégias de intensificação e, particularmente, o papel da tecnologia de mulch e de enriquecimento na economia familiar.

\section{Abstract}

Family agriculture in Cumaru, northeast of the State of Pará, established through spontaneous settlements, is a dynamic agriculture, formed through an internal development process and the migration of individuals from the northeast of Brazil. Our study evaluates the use of non-burning techniques in the development of production systems, analyzing the evolution of family establishments in Cumaru, their intensification strategy, and most particularly, the role of mulching and enrichment in family economies.
Palavras-chave

Agricultura familiar, Cumaru, tecnologia de mulch.

\section{Keywords}

Family agriculture, Cumaru, mulching. 


\section{INTRODUÇÃO}

Uma tecnologia desenvolvida para o cumprimento de parte de uma função de produção, resultante de um processo de construção social do conhecimento, pode ser caracterizada por sua amplitude de implicação ou pelo papel a que se destina. Reduzir custos de insumos, reduzir tempo de trabalho, reduzir o desgaste do trabalho e aumentar o crescimento vegetativo de uma planta são exemplos de papéis que uma tecnologia pode desempenhar.

A resolução de parte ou da totalidade de um problema de produção, no entanto, não define a eficiência ou a eficácia de uma determinada tecnologia. No caso da tecnologia de mulch, destinada ao preparo de área sem fogo, o papel da tecnologia é "realizar a retirada da vegetação secundária sem a queima, possibilitando ainda uma cobertura morta para a proteção do solo". Porém, o intuito principal dessa tecnologia é reduzir a emissão de carbono na atmosfera e manter a fertilidade. Essa tecnologia insere-se em uma estratégia de substituição tecnológica ampla, o que implica que as demais tecnologias e, conseqüentemente, todo o conjunto de práticas-técnicas deve ser ajustado a esse novo paradigma tecnológico. Trata-se, portanto, de uma transformação global dos processos e dos instrumentos de produção.

Quando esse processo ocorre no contexto da agricultura familiar, uma outra série de complicações aglutina-se. Regidos por múltiplos critérios de decisão, os estabelecimentos familiares na agricultura também têm objetivos por vezes contraditórios e concorrentes, o que torna a especificidade desses sistemas de produção um problema adicional para a efetividade de estudos comparativos. Nesse sentido, a realização de análises comparativas do desenvolvimento de tecnologias em estabelecimentos familiares torna-se uma tarefa árdua, na medida em que o controle experimental é superado pela necessidade de objetivos distintos.

A análise adicional da eficiência desses sistemas de produção em termos de obtenção de resultados econômicos e de resultados técnicos também padece da diversidade de práticas-técnicas empregadas pelos agricultores familiares.

Além disso, as condições distintas de meio físico e de estrutura de produção nesses estabelecimentos familiares exigem diferentes estratégias e formas de uso e gestão do espaço, o que acarreta a aplicação de diferentes mecanismos e de produtos objetivados na atividade produtiva, ou seja, diferentes combinações de produção e de intensidade de uso dos recursos de produção. 
Essa diferenciação na intensidade de uso dos recursos de produção torna a tecnologia "um meio distinto" de alcance de objetivos para os agricultores familiares: para uns, a busca de resultado total; para outros, um objetivo intermediário para a consecução dos objetivos finalísticos do estabelecimento familiar. Isso implica a complexificação dos instrumentos e dos métodos de análise dos estabelecimentos familiares.

Assim, a análise dos efeitos da tecnologia nos sistemas de produção baseia-se na análise da sua eficiência e da transformação dos estabelecimentos familiares no contexto, na análise da sua eficiência em relação ao uso interno e as estratégias de uso dos recursos de produção e na análise da eficiência da tecnologia de mulch em relação ao método tradicional de corte e queima.

$\mathrm{Na}$ primeira parte deste artigo, busca-se caracterizar os estabelecimentos familiares de Cumaru, município de Igarapé-Açu, no Estado do Pará, e as suas transformações recentes em termos de uso dos recursos naturais e da biomassa vegetal, principal objeto de gestão da tecnologia de mulch. Na segunda parte, a análise focaliza as estratégias de uso do trabalho e a influência da crise técnica da especialização dos sistemas de produção sobre a gestão do trabalho. Em seguida, a análise examina a influência desse processo de especialização nos resultados econômicos e as estratégias de recomposição da renda familiar. A parte seguinte mostra como as transformações globais afetarão os sistemas de produção e aponta o papel das atividades produtivas na consolidação de novo sistema. Na última parte, a análise concentra-se mais especificamente no efeito da tecnologia de mulch nos resultados técnico-econômicos dos estabelecimentos e na importância dessa tecnologia para a efetivação das práticas técnicas dos agricultores.

As considerações finais incluem sugestões de novos estudos e reflexões sobre os efeitos diretos do meio envolvente nos estabelecimentos familiares e sobre os efeitos da tecnologia no desenvolvimento do paradigma tecnológico que envolve a tecnologia de mulch.

\section{1 - CARACTERIZAÇÃO DOS SISTEMAS DE PRODUÇÃO DO CUMARU}

A comunidade de Cumaru é um exemplo de ocupação antiga no Nordeste Paraense, caracterizada pelas travessas e pelas comunidades religiosas. O estágio avançado de evolução das ocupações é bem marcado pela forte pressão demográfica, decorrente do crescimento interno das 
famílias e da conseqüente concentração populacional. Desse modo, a disponibilidade de vegetação primária nos estabelecimentos familiares é muito rara, limitada a áreas de igapós, fortemente antropizadas. A capoeira é, então, a principal vegetação existente nesses estabelecimentos, distribuída em diferentes estágios de crescimento.

Para definir os estabelecimentos que serão alvo de uma introdução tecnológica, é preciso considerar, além da necessidade interna de mudança, a adequação da nova tecnologia ao sistema de produção em questão, integrada ao conjunto de tecnologias relativas ao processo de produção, e as condições efetivas de decisão dos agricultores familiares.

Das 24 famílias estudadas, 12,5\% formaram seus estabelecimentos até os anos 50, 25\% constituíram seus estabelecimentos nas décadas de 60 e 70 e as 62,5\% famílias restantes o fizeram nas décadas de 80 e 90. Isso não significa, no entanto, que haja um fluxo migratório recente na região. Quanto à origem, os chefes da maior parte dessas famílias nasceram em Igarapé-Açu mesmo: 17 chefes de família nasceram no próprio município, 3 nasceram em municípios vizinhos (2 em Santa Maria do Pará e 1 em Castanhal). Portanto, apenas 4 são migrantes de outras regiões, mais especificamente 3 do Ceará e 1 do Amazonas.

Considerando-se a geração anterior, constata-se que o pai de 8 dos 17 chefes de família nascidos em Igarapé-Açu nasceu nesse mesmo município e o pai de 4 nasceu em municípios vizinhos. Portanto, pode-se afirmar que essas famílias apresentam uma história de ocupação antiga nessa área, já que a maioria dessas famílias é originária da própria região.

Uma primeira questão refere-se, pois, ao processo de formação de novos estabelecimentos nas décadas mais recentes. Na maioria dos casos, esse processo está relacionado com a formação de novas famílias, cujos membros se separaram dos pais e passaram a constituir novos estabelecimentos familiares na região. Essa constatação é reforçada pelo fato de 17 das 24 famílias estudadas terem recebido suas terras por herança ou doação de familiares. Mesmo nas famílias estabelecidas nas décadas mais antigas, o acesso à terra por herança ou doação já era significativo, o que reforça os vínculos geracionais na ocupação da terra na região na segunda metade do século XX (Tabela 1).

As observações anteriores suscitam uma questão importante, relativa às conseqüências dessa dinâmica de formação de novos estabelecimentos no tamanho médio da terra de cada família. Para se ter uma idéia desse processo, é necessário definir a situação atual dos estabelecimentos familiares estudados, no que se refere ao tamanho da propriedade. Além disso, é preciso examinar o histórico da obtenção e da utilização da terra pelas diversas famílias estudadas. 
Tabela 1: Meio de acesso à terra pelas famílias na comunidade de Cumaru

\begin{tabular}{cccccc}
\hline Chegada à & \multicolumn{5}{c}{ Meio de acesso à terra (quantidade de famílias) } \\
\cline { 2 - 6 } terra & Compra & Doação & Herança & Ocupação pacífica & Total \\
\hline 1950 & 1 & 0 & 2 & 0 & 3 \\
1960 & 0 & 1 & 1 & 0 & 2 \\
1970 & 2 & 0 & 2 & 0 & 4 \\
1980 & 1 & 0 & 6 & 0 & 7 \\
1990 & 2 & 3 & 2 & 1 & 8 \\
\hline Total & 6 & 4 & 13 & 1 & 24 \\
\hline
\end{tabular}

Fonte: Pesquisa de campo (2000).

A área total declarada atualmente pelos 24 estabelecimentos familiares estudados é de 428,8 ha, o que representa uma área média de 17,87 ha por estabelecimento. No entanto, quando se analisam os dados com base na declaração da soma das parcelas sobre as quais têm controle efetivo, a superfície total declarada é de 363,79 ha, o que representa um tamanho médio por estabelecimento de 15,2 ha. Excluindo-se os dois casos extremos - a família n. ${ }^{\circ}$ 19, que possui 100 ha, ou seja, 4 lotes da ocupação original, e, no pólo oposto, a família n. ${ }^{\circ}$ 12 , com apenas 0,5 ha, ou seja, praticamente apenas a área ocupada pela casa de moradia e por um pequeno roçado de mandioca -, a área total ocupada atualmente pelas 22 famílias restantes é de 263,29 ha, uma média de 12 ha por estabelecimento.

Considerando que parte desses lotes é resultado do arrendamento de terras de fora da propriedade das famílias, o tamanho médio do estabelecimento apresenta uma terceira redução, passando a ser de 11,0 ha por família. A ampliação dos minifúndios na região parece ser muito importante, considerando a amostra analisada. Mais da metade das famílias possui menos de $50 \%$ do controle sobre o tamanho do lote padrão de ocupação.

Conseqüentemente, observa-se uma diminuição das áreas de reserva, ou melhor, das áreas de capoeira grossa, e um aumento da área de capoeira fina, o que significa que o tempo de pousio necessário para a obtenção de uma boa fertilidade do meio não está sendo considerado pelos agricultores. Tal situação pode ser explicada pelo fato de possuírem poucas áreas, sendo grande parte dos lotes explorada quase sem pousio. A queda de $57 \%$ da área total do estabelecimento para $37 \%$ de áreas em pousio, uma redução de 6,3 ha para 4 ha, em média por estabelecimento, constitui uma situação delicada nas condições efetivas de gestão do solo (Tabela 2). 
Tabela 2: Área média por estabelecimento e área média em pousio (ha)

\begin{tabular}{cccc}
\hline Ano & Área média do lote & Área média de pousio & Total do pousio \\
\hline 1999 & 11,0 & 6,3 & $57 \%$ \\
2000 & 11,0 & 5,6 & $51 \%$ \\
2001 & 11,0 & 4,8 & $44 \%$ \\
2002 & 11,0 & 4,3 & $40 \%$ \\
2003 & 10,8 & 4,0 & $37 \%$ \\
\hline
\end{tabular}

Fonte: Banco de dados do Projeto SHIFT.

A análise da evolução do uso das parcelas de 21 estabelecimentos demonstra uma forte redução da área de capoeira média, uma leve redução da capoeira grossa e um incremento forte da capoeira fina. As parcelas de capoeira média decresceram de 134,4 para 37 hectares em um período de 10 anos, restando apenas $28 \%$ do que havia anteriormente. A área total de capoeira grossa manteve-se estável até 1999, quando a superfície dessa categoria teve um pequeno decréscimo de $20 \%$. Por outro lado, houve um aumento da capoeira fina de 13,3 para 61,4 hectares no mesmo período, o que representa um incremento de 4,6 vezes o tamanho inicialmente disponível (Figura 1).

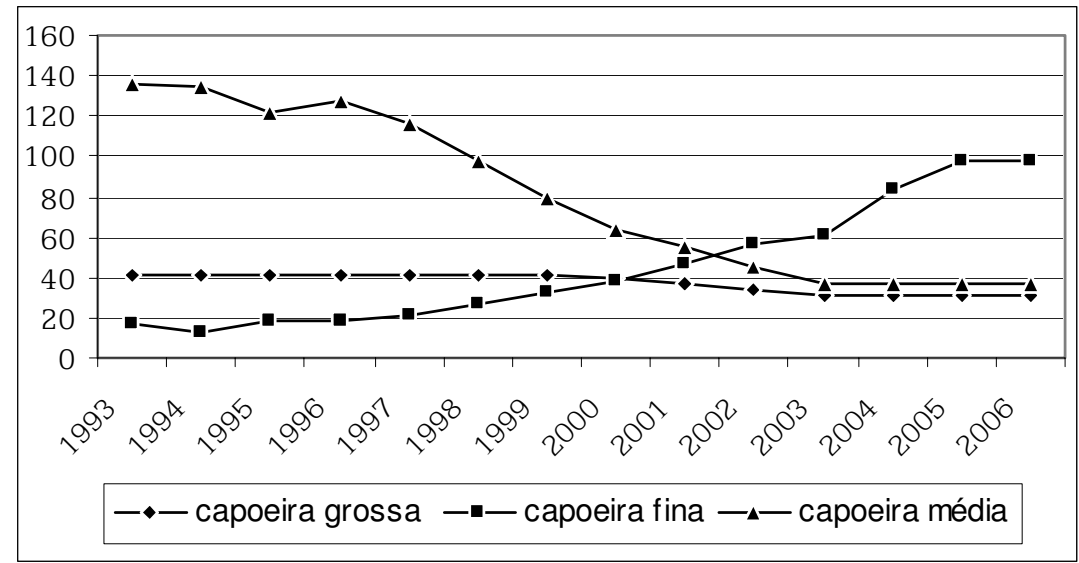

Figura 1: Evolução da capoeira e perspectivas de gestão do solo em 21 estabelecimentos familiares de Igarapé-Açu, PA (ha/ano).

Fonte: Banco de dados Projeto SHIFT.

Paradoxalmente, os agricultores esperam, para os próximos cinco anos de uso do solo, um incremento na proporção de capoeira fina e uma estabilização das parcelas de capoeira média e grossa e, ao mesmo tempo, a redução da somatória das parcelas cultivadas.

A análise do comportamento das principais formas de uso do solo dos 21 estabelecimentos mostra uma clara redução, entre 1993 e 2003, 
da área disponível para pousio, que passou de 80\% para 61\% da área total utilizada ${ }^{1}$. Essa redução é acompanhada por um crescimento das parcelas de cultivo anual e de cultivos perenes e por uma leve redução das culturas semiperenes. Porém, também se torna evidente uma vontade de redução dos cultivos anuais para os próximos anos, acompanhada pelo incremento das parcelas de pousio. Esse mesmo fenômeno também é declarado para os cultivos semiperenes, com uma intenção de estabilização das parcelas de cultivos perenes (Figura 2).

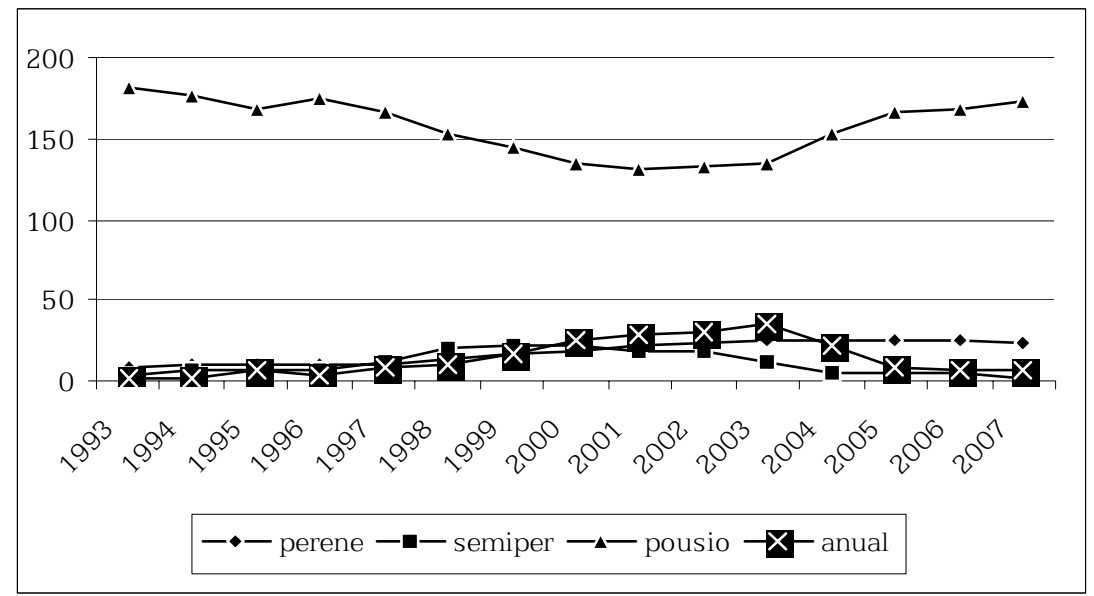

Figura 2: Evolução da ocupação do solo por categoria de utilização da superfície.

Fonte: Banco de dados Projeto SHIFT.

Contudo, os dados do período efetivo de acompanhamento das parcelas (1999 a 2003) apontam para um incremento forte - 112\% dos cultivos anuais nos 21 estabelecimentos: de 16,7 hectares em 1999 passaram para 35,3 hectares em 2003. Além disso, houve uma redução das áreas cultivadas com maracujá, por causa de pragas e doenças (em 1999, existiam 21,5 hectares plantados dessas culturas e, em 2003, as áreas diminuíram para 11,3 hectares). Já os cultivos perenes tiveram um crescimento de 48\%, passando de 16,5 hectares em 1999 para 24,4 em 2003 (Figura 3).

A crise técnica gerada pela virose do maracujá provocou uma redução da área cultivada dessa cultura, que passou de 39 hectares em 2000 para 15 hectares em 2003 nos 24 estabelecimentos. Como estratégia de recomposição da renda familiar, além das culturas anuais,

1 Excluem-se desse cálculo as parcelas não utilizáveis para fins agrícolas, como é o caso dos igapós. 
que não possibilitam a reposição adequada da remuneração do trabalho que o maracujá permitia, ganham força a cultura do urucum, que permite uma reposição parcial da renda sem um alto custo de investimento, e a das hortaliças: essas culturas passaram de 2 ha em 1999 para 9 ha em 2003 e de 3 ha em 1999 para 6 ha em 2003, respectivamente (Tabela 5).

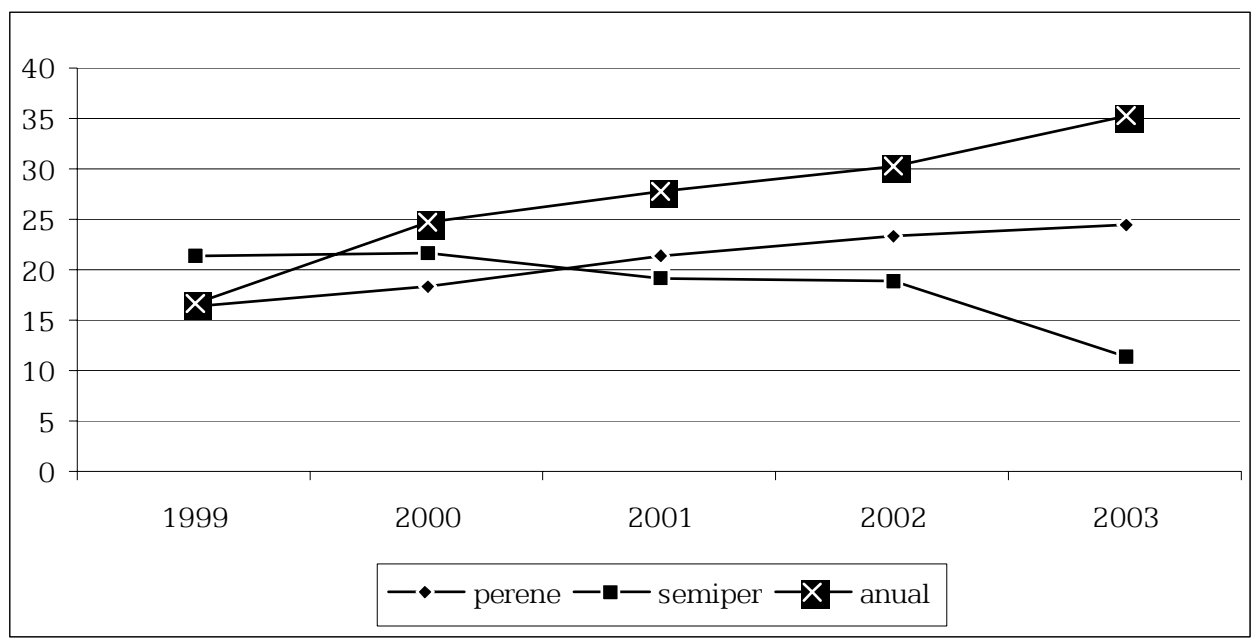

Figura 3: Evolução das parcelas cultivadas por categoria de cultivo nos 21 estabelecimentos do Cumaru (de 1999 a 2003).

Fonte: Banco de dados do Projeto SHIFT.

É interessante destacar que a mudança nas atividades e na proporção das culturas acontece na fase crítica da crise da cultura do maracujá - um momento importante para a inovação e a modificação das formas de produzir. Um outro aspecto importante dessa mudança é a busca de atividades que exigem baixos níveis de investimentos e alta carga de trabalho, como as culturas do urucum e das hortaliças.

Com base na análise da evolução do uso do solo e da vegetação, cabe ressaltar dois aspectos relativamente importantes:

a) há uma intensificação do trabalho nas parcelas cultivadas com culturas perenes, quando a renda familiar apresenta uma recuperação após as perdas decorrentes da redução da área cultivada de maracujá - caso semelhante ocorreu no município de Capitão Poço, na passagem do roçado para os cultivos perenes (COSTA, 1998);

b) se a tendência de evolução das parcelas cultivadas se mantiver, haverá uma intensificação do uso do solo (maior média de área cultivada por ano), com uma redução das parcelas de pousio. 
Tabela 3: Evolução do povoamento vegetal nos 24 estabelecimentos de Cumaru

\begin{tabular}{|c|c|c|c|c|c|}
\hline Povoamento & 1999 & 2000 & 2001 & 2002 & 2003 \\
\hline$\overline{\text { Capoeira grossa }}$ & 22 & 19 & 15 & 11 & $\overline{7}$ \\
\hline Capoeira média & 82 & 60 & 39 & 20 & 11 \\
\hline Capoeira fina & 46 & 56 & 61 & 73 & 79 \\
\hline Roça & 29 & 34 & 42 & 46 & 59 \\
\hline Maracujá & 32 & 39 & 33 & 29 & 15 \\
\hline Pimenta-do-reino & 9 & 12 & 12 & 13 & 12 \\
\hline Sítio & 21 & 22 & 22 & 22 & 25 \\
\hline Urucum & 2 & 1 & 5 & 8 & 9 \\
\hline Enriquecimento & 0 & 0 & 1 & 5 & 11 \\
\hline Feijão & 2 & 0 & 8 & 5 & 1 \\
\hline Igapó & 6 & 6 & 6 & 6 & 6 \\
\hline Murici & 1 & 1 & 1 & 1 & 1 \\
\hline Laranja & 0 & 2 & 3 & 3 & 3 \\
\hline Coco & 0 & 0 & 0 & 0 & 0 \\
\hline Ingá & 0 & 0 & 0 & 0 & 0 \\
\hline Cupuaçu & 0 & 1 & 1 & 1 & 0 \\
\hline Limão & 0 & 2 & 1 & 1 & 1 \\
\hline Açaí & 0 & 0 & 0 & 0 & 0 \\
\hline Banana & 0 & 1 & 1 & 1 & 2 \\
\hline Capim & 3 & 2 & 2 & 2 & 2 \\
\hline Shift ${ }^{*}$ & 1 & 2 & 2 & 2 & 2 \\
\hline Pimenta-doce & 0 & 0 & 1 & 1 & 0 \\
\hline Berinjela & 0 & 0 & 1 & 0 & 0 \\
\hline Mamão & 1 & 0 & 1 & 1 & 1 \\
\hline Maxixe & 0 & 0 & 0 & 0 & 2 \\
\hline Macaxeira & 0 & 0 & 0 & 4 & 1 \\
\hline Arroz & 2 & 0 & 0 & 0 & 2 \\
\hline Milho & 0 & 0 & 0 & 2 & 2 \\
\hline Horta & 3 & 3 & 5 & 5 & 6 \\
\hline Melancia & 1 & 0 & 0 & 1 & 0 \\
\hline TOTAL & 263 & 263 & 263 & 263 & 260 \\
\hline
\end{tabular}

Fonte: Banco de dados do Projeto SHIFT .

* Área arrendada para o projeto SHIFT.

Nesse segundo caso, se as novas culturas não conseguirem recuperar as perdas de renda da cultura do maracujá, haverá uma extensificação do trabalho por parcelas, com uma intensificação do uso do solo no conjunto do estabelecimento (parcelas com menos tempo de pousio).

As implicações desses processos para a sustentabilidade da fertilidade das capoeiras nos estabelecimentos familiares do Cumaru 
podem ser altamente relevantes, considerando-se as tendências atuais de uso do solo. Essas tendências podem ser esclarecidas por meio da análise dos impactos sobre a renda e sobre o trabalho familiar.

Do mesmo modo, as implicações desses processos para o estabelecimento de tecnologias alternativas (como a tecnologia de mulch) também podem ser diretamente afetadas pelos caminhos trilhados nesses estabelecimentos.

A tecnologia de mulch prevê, em condições de redução da capacidade de recomposição da fertilidade da capoeira, o uso do solo após trituração por dois anos, seguido de um pousio de mais dois anos para a realização de um novo ciclo de trituração-cultivo-pousio (PROJETO SHIFT, 2000). A adaptação da tecnologia de mulch às condições dos sistemas de produção dependeria, portanto, não somente de uma aproximação das formas de gestão do uso do solo nesses sistemas, mas também de condições limitantes de capoeira para a viabilidade dos ciclos de pousio nesses estabelecimentos.

A análise da gestão do solo nesses estabelecimentos permite verificar que, dos 24 estabelecimentos da amostra, 11 (46\%) apresentam menos de 1/3 da área em pousio e outros 4 (17\%) apresentavam áreas inferiores a $1 / 3$ do tamanho médio das roças anuais nos últimos cinco anos, o que impossibilitaria o estabelecimento de ciclos de pousio e cultivo apoiado na tecnologia de mulch. Dos demais estabelecimentos, 1 (4\%) realizava roças muito pequenas, 4 (17\%) possuíam menos de 15 hectares e tiveram uma redução forte das capoeira nos últimos cinco anos (de 40 a 96\% da capoeira disponível entre 1999 e 2003). Apenas 6 (25\%) possuíam mais de 15 hectares e dispunham de mais de 66\% de capoeira, em relação à área total.

O exame das modalidades de uso do solo demonstra que o grau de utilização médio anual do solo avançou de $40 \%$ para $60 \%$ em cinco anos, o que representa aproximadamente $2 / 3$ do tempo da terra em uso. As culturas anuais apresentaram um incremento médio de 100\% no tamanho praticado entre 1999 e 2003, passando de 11\% para 22\% da superfície média dos estabelecimentos. Contudo, a pressão relativa sobre as áreas de pousio tem sido minimizada em função da busca do arrendamento de terras fora da comunidade como forma de manutenção da cultura do maracujá. Essas terras arrendadas já representam 15\% das novas parcelas implantadas por essas famílias.

De um modo geral, a maioria desses estabelecimentos já realiza práticas de intensificação do uso do solo por meio de diferentes combinações de cultivo, como maracujá x mandioca x pousio (2 a 4 anos de cultivo e 4 anos de pousio), maracujá x pimenta-do-reino x mandioca 
$\mathrm{x}$ pousio ( 8 anos de cultivo e 4 de pousio), mandioca $\mathrm{x}$ mandioca $\mathrm{x}$ mandioca $x$ pousio ( 3 a 5 anos de cultivo e 4 de pousio), além de combinações mais específicas, como mandioca x urucum ou roça x horta $\mathrm{x}$ culturas semiperenes x culturas perenes, horta x culturas perenes. Essa diversidade de formas de gestão do solo demonstra, entre outras coisas, tentativas de inovação nas formas de uso do solo por essa agricultura familiar, dadas as condições limitantes das superfícies disponíveis.

Para a grande maioria das 24 famílias acompanhadas (74\%), a aplicação continuada da tecnologia de mulch não permite resolver o problema da perda de fertilidade, uma vez que a taxa de uso é superior à disponibilidade de áreas em pousio. Conhecer o grau do controle que essas famílias têm sobre o espaço é importante para a análise da adaptabilidade da tecnologia, visto que essas famílias tendem a distribuir no grupo familiar as áreas disponíveis para o cultivo.

Para se identificar como tal, o agricultor precisa estabelecer uma ligação afetiva com a terra. Declarar-se agricultor implica declarar a posse da terra, informação importante na seleção de famílias beneficiárias de políticas públicas.

A elaboração do parcelário dos estabelecimentos familiares mostra a gravidade do quadro fundiário na região bragantina. Existe uma tendência de minifundização que mascara o grau de intensidade do uso da terra nesses estabelecimentos familiares. Situações semelhantes têm sido observadas em comunidades rurais de Bragança, Santo Antônio do Tauá e Ourém (FIGUEIREDO, 1998; FIGUEIREDO, 2004; SIMÕES; FIGUEIREDO, 2001).

\subsection{O USO DO TRABALHO FAMILIAR: SAZONALIDADE DO TRABALHO E A CRISE TÉCNICA DA ESPECIALIZAÇÃO}

A análise da constituição e da composição das famílias do Cumaru aponta um grau médio de desenvolvimento demográfico: 6,5 pessoas por estabelecimento (família nuclear), com idade média de 25,4 anos. A alta concentração de pessoas na idade produtiva $(74,4 \%)$ e o parentesco entre esses agricultores aumenta o estabelecimento de muitas atividades na forma de troca de dias, produção de meia e outras relações de produção não monetárias (Tabela 4).

De um modo geral, isso tende a permitir uma melhor gestão do trabalho familiar nesses estabelecimentos, reduzindo os efeitos dos 
constrangimentos decorrentes das atividades ou das práticas concentradoras de trabalho.

Tabela 4: Trabalho familiar potencial por faixa etária nos 24 estabelecimentos familiares de Cumaru

\begin{tabular}{lcr}
\hline Faixa etária & $N^{\circ}$ de pessoas & Total (\%) \\
\hline 0 a 6 anos & 11 & $6,9 \%$ \\
7 a 12 anos & 24 & $15,0 \%$ \\
13 a 16 anos & 25 & $15,6 \%$ \\
17 a 50 anos & 83 & $51,9 \%$ \\
51 a 65 anos & 11 & $6,9 \%$ \\
$>65$ anos & 6 & $3,8 \%$ \\
\hline Total de pessoas & 160 & $100,00 \%$ \\
\hline
\end{tabular}

Fonte: Banco de dados do Peasant.

Um dos primeiros aspectos que se desejava abordar com mais clareza eram os fluxos de trabalho aplicado pelos agricultores nos estabelecimentos familiares de Cumaru. A maioria dos estudos recentes afirma que as atividades agropecuárias diferenciam-se pela forte influência do clima na gestão do trabalho. Esse fator limitaria a agricultura ao desenvolvimento de es

Uma primeira análise, com ba: dos estabelecimentos de Cumaru, a trabalho familiar mensal, com maior outubro e menores cotas no final do verão (novembro a dezembro) (Figur

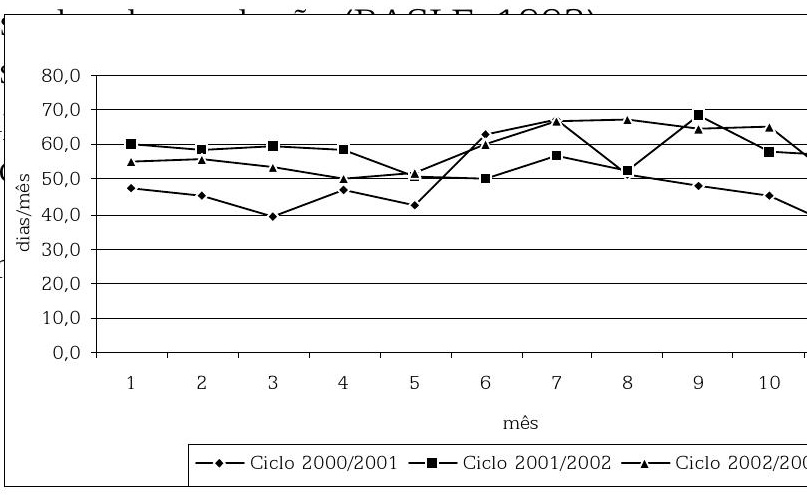

Figura 4: Sazonalidade do trabalho familiar em Cumaru (média mensal por estabelecimento).

Porém, quando se analisa o uso do trabalho familiar no estabelecimento, excluindo-se as atividades domésticas, observa-se uma 
forte variabilidade mensal do trabalho familiar aplicado, havendo variações de 100\% entre o máximo e o mínimo de trabalho mensal. Além da variabilidade mensal, observa-se ainda uma variabilidade anual decorrente dos fluxos de trabalho aplicado nas principais culturas de acordo com os fluxos climáticos (Figura 5).

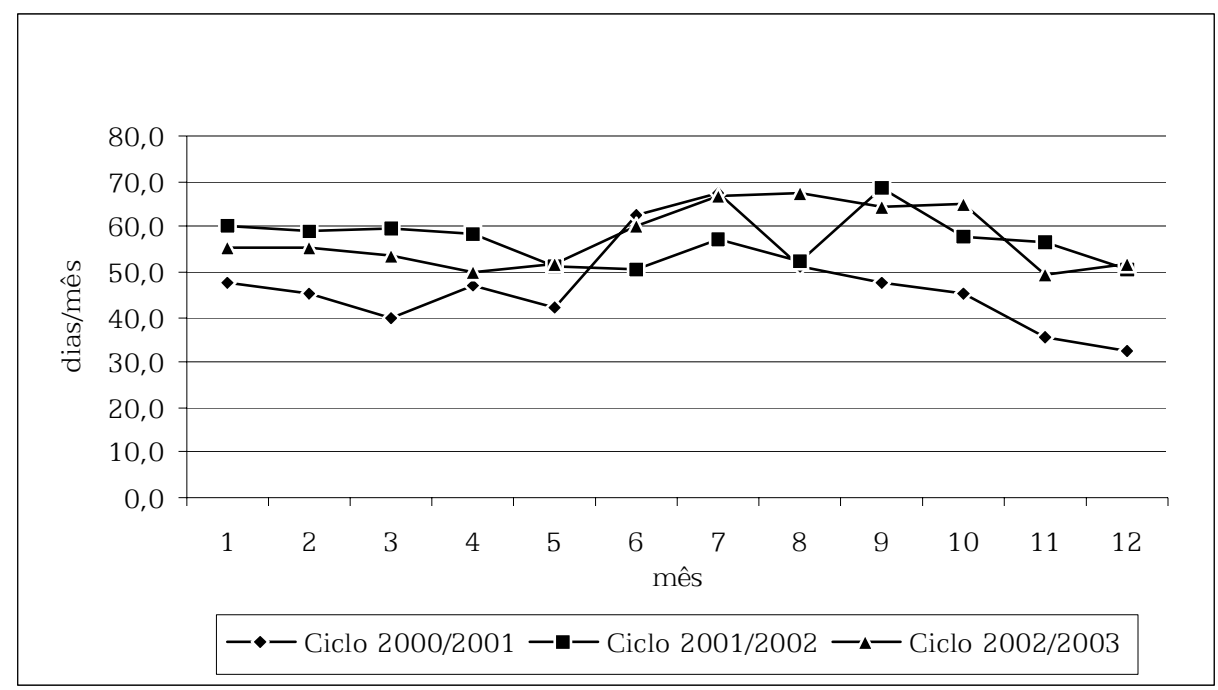

Figura 5: Sazonalidade do trabalho familiar, excluído o trabalho doméstico, em Cumaru (média mensal por estabelecimento).

A sazonalidade do trabalho está bem presente nos resultados desses estabelecimentos. Contudo, observam-se mecanismos internos de superação dos fluxos pela diversificação das atividades produtivas. Porém, a susceptibilidade das famílias em termos de gestão do trabalho parece ser relativamente importante quando se analisa a variação de trabalho anual, um indicativo de mudanças estruturais na organização do trabalho desses estabelecimentos.

Uma primeira análise permite constatar um leve crescimento do trabalho familiar por estabelecimentos entre os ciclos 2000/2001 e 2001/ 2002, com uma estabilização entre os ciclos 2001/2002 e 2002/2003, em média de 650 dias/família/ano. Mas uma análise detalhada da finalidade deste trabalho mostra que a agricultura própria ocupava 75\% do tempo total de trabalho familiar no primeiro ciclo, passando a ocupar $59 \%$ no segundo ciclo e 46\% no último ano. Essa redução é acompanhada de um crescimento importante do trabalho dedicado à casa e ao pomar (8,2\%, 19,8\% e $31.6 \%$ nos três ciclos, respectivamente) e do tempo destinado ao trabalho assalariado na agricultura $(7,7 \%, 9,6 \%$ e 13,7\%, respectivamente) (Tabela 5). 
Tabela 5: Distribuição do trabalho (W) familiar por finalidade de aplicação nos estabelecimentos familiares de Cumaru de acordo com o ciclo agrícola (dias/ano).

\begin{tabular}{l|r|r|r|r|r}
\hline Finalidade do W & $2000 / 2001$ & $2001 / 2002$ & $2002 / 2003$ & Média Anual & $\%$ Total \\
\hline Agric. própria & $9.867,7$ & $9.546,3$ & $7.315,0$ & $8.909,6$ & $59,1 \%$ \\
Casa & $1.071,2$ & $3.208,5$ & $5.043,6$ & $3.107,8$ & $20,6 \%$ \\
Agric. terceiros & $1.006,5$ & $1.553,0$ & $2.182,5$ & $1.580,7$ & $10,5 \%$ \\
Agrícola terceiros & $1.038,5$ & $1.605,0$ & $1.074,0$ & $1.239,2$ & $8,2 \%$ \\
Extrativismo & 133,9 & 142,0 & 132,0 & 136,0 & $0,9 \%$ \\
Agrícola própria & - & 69,0 & 168,0 & 79,0 & $0,5 \%$ \\
Comunidade & 5,0 & 56,5 & 8,0 & 23,2 & $0,2 \%$ \\
Extrat. terceiros & - & 8,0 & 19,0 & 9,0 & $0,1 \%$ \\
\hline Total global & $13.122,8$ & $16.188,3$ & $15.942,1$ & $15.084,4$ & $100,0 \%$ \\
\hline
\end{tabular}

Fonte: Banco de dados do Projeto SHIFT.

O exame das principais finalidades de aplicação do trabalho familiar permite constatar uma mudança no uso do trabalho dos agricultores - aumenta o tempo total aplicado por estabelecimentos - e, ao mesmo tempo, na finalidade do uso desse trabalho. Apesar da flutuação do tempo total de trabalho familiar por estabelecimento, com uma forte queda do trabalho dedicado à agricultura própria, há um crescimento significativo do tempo de trabalho destinado às atividades domésticas e ao pomar e também às atividades agrícolas voltadas para terceiros, isto é, ao trabalho assalariado na agricultura (Figura 6).

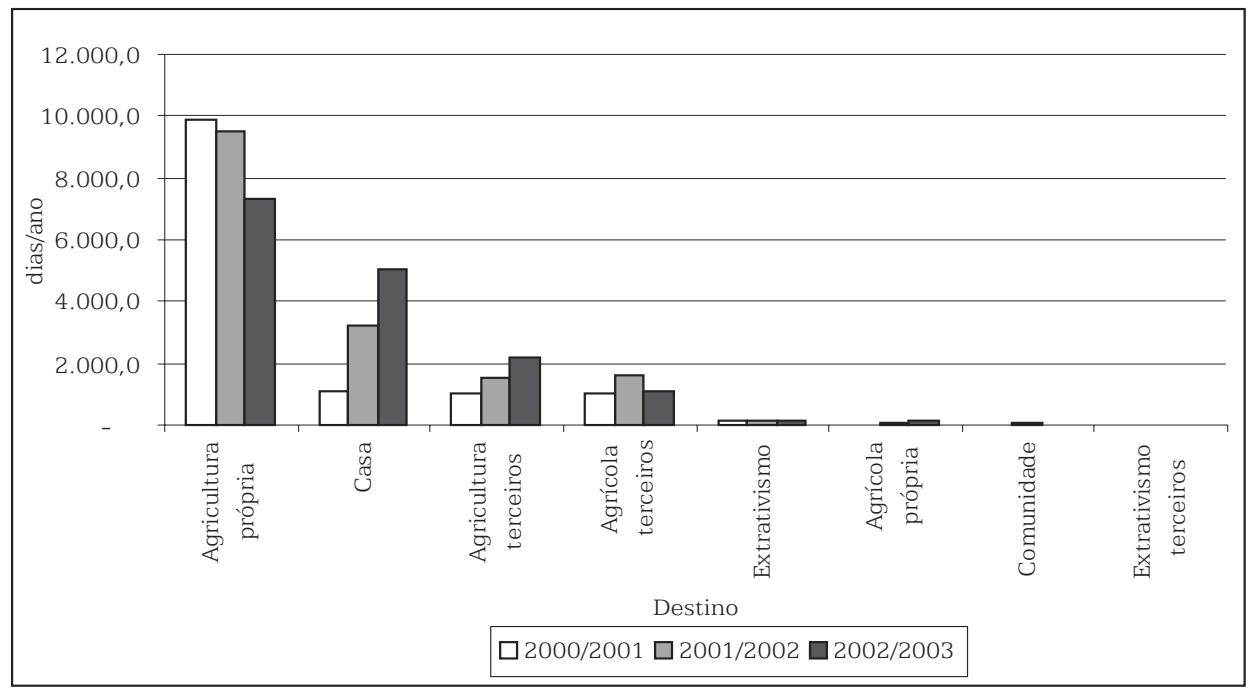

Figura 6: Distribuição do trabalho (W) familiar nos estabelecimentos de Cumaru por ciclo agrícola (dias/ano). 
Se o tempo de trabalho na agricultura é relativamente importante, a análise das atividades desenvolvidas permite identificar com mais precisão as características das mudanças nos estabelecimentos. Em média, 16,9\% do trabalho familiar destinam-se à realização de capinas, com uma tendência de redução do tempo médio anual entre os ciclos de 2000/2001 (3056 dias), de 2001/2002 (2417,5 dias) e de 2002/2003 (2256,5 dias). Essa redução é relativamente importante nas atividades ligadas à cultura do maracujá, como é o caso das atividades de pulverização, adubação, ramagem, estaqueamento, abertura de gavetas, amarração e aperto de fios de aço. Apenas a atividade de polinização apresentou um crescimento do tempo de trabalho familiar aplicado entre 2000/2001 e 2001/2002, com uma queda consecutiva entre 2001/2002 e 2002/2003. É possível que esse crescimento do tempo destinado à polinização seja uma estratégia de recomposição rápida das perdas decorrentes das doenças do maracujazeiro.

Observa-se um processo semelhante de flutuação do trabalho quando se analisa o trabalho adquirido por essas famílias. Há um aumento do trabalho assalariado médio por estabelecimento, em decorrência da redução do trabalho contratado para a cultura do maracujazeiro, seguido de um aumento de trabalho nas atividades de colheita, beneficiamento e preparo de área das culturas da pimenta-doreino e da mandioca, respectivamente. Observa-se, entre o segundo e o terceiro ciclo, uma nova redução desse fluxo de trabalho assalariado.

De modo geral, o fluxo de trabalho total nos estabelecimentos familiares de Cumaru tende para uma redução do tempo aplicado na cultura do maracujazeiro, com um acréscimo no trabalho destinado a atividades não agrícolas e uma flutuação no tempo aplicado no roçado ou nas atividades vinculadas à produção agrícola, como a comercialização, os serviços gerais, a construção civil e os fretes (Tabela 6).

Analisando o total de trabalho na agricultura, observa-se uma redução dos fluxos globais para as atividades produtivas dos estabelecimentos e um aumento do trabalho familiar contratado por outros produtores. Dessa forma, o trabalho aplicado nas culturas do maracujá, da mandioca e das hortaliças tende a diminuir durante os três ciclos agrícolas analisados, enquanto o trabalho dedicado à pimenta-do-reino, ao milho, ao feijão e à pimenta-doce é flutuante.

Juntas, todas essas culturas representam 97,6\% do tempo de trabalho da agricultura própria, que tende a crescer entre o primeiro e o segundo ciclo e entre o segundo e o terceiro ciclo. Porém, o maracujá ainda ocupou 46,6\% do tempo de trabalho na agricultura 
nesses três ciclos, seguido da mandioca, que tomou 27,6\% do tempo total (Tabela 7).

Tabela 6: Distribuição do trabalho familiar e do trabalho contratado por ano agrícola nos 24 estabelecimentos familiares de Cumaru (dias/ano).

\begin{tabular}{|c|c|c|c|}
\hline \multirow{2}{*}{ Tipo de atividade } & \multicolumn{3}{|c|}{ Trabalho total aplica } \\
\hline & $2000 / 2001$ & $2001 / 2002$ & $2002 / 2003$ \\
\hline Lar/Pomar & $1.013,5$ & $3.266,5$ & $5.212,0$ \\
\hline Capina & $3.613,8$ & $2.994,4$ & $2.492,5$ \\
\hline Colheita & $2.070,0$ & $3.200,1$ & $2.969,2$ \\
\hline Beneficiamento & $1.268,5$ & $1.935,5$ & $1.606,5$ \\
\hline Polinização & $1.357,0$ & $1.965,7$ & $1.450,5$ \\
\hline Plantio & 775,6 & 461,0 & 578,0 \\
\hline Horta* $^{*}$ & 644,0 & 195,0 & - \\
\hline Construção civil & 268,5 & 554,0 & 303,0 \\
\hline Pulverização & 558,3 & 447,9 & 149,0 \\
\hline Comércio & 362,0 & 392,0 & 219,0 \\
\hline Adubação & 339,2 & 204,1 & 194,3 \\
\hline Ramagem & 315,0 & 224,0 & 36,5 \\
\hline Limpeza & 186,7 & 93,9 & 281,6 \\
\hline Irrigação & 166,0 & 169,5 & 276,0 \\
\hline Poda & 48,5 & 196,8 & 245,0 \\
\hline Servente & 35,0 & 169,0 & 282,0 \\
\hline Broca & 378,0 & 179,0 & 180,7 \\
\hline Cavação & 146,1 & 347,3 & 85,0 \\
\hline Serviço público & 45,0 & 283,0 & 117,0 \\
\hline Professor(a) & 122,0 & 128,0 & 130,0 \\
\hline Administração & 60,0 & 79,0 & 168,0 \\
\hline \multicolumn{3}{|c|}{ 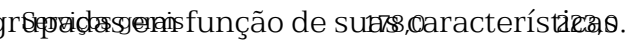 } & 88,0 \\
\hline Enfiar estaca & 127,1 & 106,8 & 80,0 \\
\hline Amarração & 174,3 & 64,0 & 2,5 \\
\hline Carvão & 93,7 & 79,5 & 82,5 \\
\hline Entrevista & 120,0 & 70,0 & 12,0 \\
\hline Colocar arame & 105,0 & 88,0 & 19,0 \\
\hline
\end{tabular}


Tabela 7: Fluxos de trabalho aplicado no sistema de culturas dos 24 estabelecimentos familiares do Cumaru (dias/ciclo agrícola).

\begin{tabular}{|l|r|r|r|r|r|}
\hline Cultura & $2000 / 2001$ & $2001 / 2002$ & $2002 / 2003$ & Média anual & da média \\
\hline Maracujá & $6.029,5$ & $5.741,0$ & $3.329,8$ & $5.033,4$ & $46,6 \%$ \\
\hline Mandioca & $3.431,3$ & 2954,2 & 2558,8 & $2.981,4$ & $27,6 \%$ \\
\hline Horta & $1.385,0$ & $1.274,5$ & $1.053,4$ & $1.237,6$ & $11,5 \%$ \\
\hline Pimenta-do-reino & 813,0 & 363,0 & 540,8 & 572,3 & $5,3 \%$ \\
\hline Milho & 340,0 & 239,3 & 279,8 & 286,3 & $2,7 \%$ \\
\hline Feijão & 269,4 & 400,6 & 147,5 & 272,5 & $2,5 \%$ \\
\hline Pimenta-doce & 2025 & 206,7 & 45,3 & 151,5 & $1,4 \%$ \\
\hline Urucum & 12,0 & 86,8 & 68,5 & 55,8 & $0,5 \%$ \\
\hline Abacate & 720 & 42,8 & - & 38,3 & $0,4 \%$ \\
\hline Beringela & 19,5 & 723 & 11,0 & 34,3 & $0,3 \%$ \\
\hline Mamão & 8,5 & 30,5 & 48,0 & 29,0 & $0,3 \%$ \\
\hline Macaxeira & 28,0 & 28,5 & 12,0 & 22,8 & $0,2 \%$ \\
\hline Arroz & 1,5 & 26,3 & 28,0 & 18,6 & $0,2 \%$ \\
\hline Maxixe & 7,0 & 19,3 & 19,0 & 15,1 & $0,1 \%$ \\
\hline Manga & 10,0 & 3,6 & 24,6 & 12,7 & $0,1 \%$ \\
\hline Banana & 6,6 & 25,0 & 4,0 & 11,9 & $0,1 \%$ \\
\hline Limão & - & 11,0 & 4,0 & 5,0 & $0,0 \%$ \\
\hline Coentro & 17,0 & 5,0 & - & 7,3 & $0,1 \%$ \\
\hline Melancia & - & 7,3 & 6,0 & 4,4 & $0,0 \%$ \\
\hline Alface & 15,0 & 1,0 & - & 5,3 & $0,0 \%$ \\
\hline Pepino & 7,3 & 2,5 & - & 3,3 & $0,0 \%$ \\
\hline Outras & 6,0 & 1,0 & 2,0 & 3,0 & $0,0 \%$ \\
\hline Total global & 12675,0 & $11.541,0$ & 8180,3 & $10.798,7$ & $100,0 \%$ \\
\hline
\end{tabular}

Verifica-se uma redução generalizada do tempo de trabalho das principais atividades de cultivo dos estabelecimentos, uma redução significativa do trabalho aplicado ao sistema de culturas desses agricultores.

Que fatores seriam responsáveis pelo aumento da área média cultivada por estabelecimento, acompanhado de uma redução do trabalho por parcela (intensificação absoluta $^{2}$ do uso do solo e extensificação do trabalho na agricultura)? Como essas mudanças influem na organização econômica desses estabelecimentos? De que forma esses processos afetam a decisão de inovação ou de adoção de uma tecnologia?

2 A intensificação absoluta aqui mencionada diz respeito ao tamanho de área cultivada por ano e não ao tempo de cultivo nessas áreas. 


\subsection{A CRISE DA ESPECIALIZAÇÃO E AS ESTRATÉGIAS DE RECOMPOSIÇÃO DA RENDA FAMILIAR}

A análise dos fluxos financeiros globais do conjunto de estabelecimentos familiares observados no Cumaru mostra uma dinâmica semelhante à imposta à agricultura familiar na economia moderna, isto é, uma tendência de apropriação do trabalho. No ciclo 2000/2001, a renda familiar líquida de uma família era de R\$ 8440,00/ano, tendo aumentado para R \$9700,00/ano no ciclo 2001/2002, sofrendo uma nova redução no ciclo 2002/2003 e mantendo-se em R\$ 8610,00/ano. No entanto, o valor efetivamente recebido por um dia trabalhado passou de $R \$ 16,58$ para $R \$ 14,05$ e depois para $R \$ 12,94$ entre os três ciclos, respectivamente. Apesar da flutuação da renda líquida interanual, a perda do valor do dia de trabalho é uma constante nesses estabelecimentos.

Paralelamente ao processo de redução do trabalho familiar, do trabalho total aplicado nas atividades agropecuárias e do valor do dia de trabalho, observa-se uma redução do valor bruto da produção (VBP) familiar proveniente das culturas permanentes, uma flutuação do VBP das culturas temporárias e um crescimento do VBP proveniente das atividades realizadas para terceiros, das aposentadorias e do apoio externo (principalmente os apoios governamentais) (Figura 7).

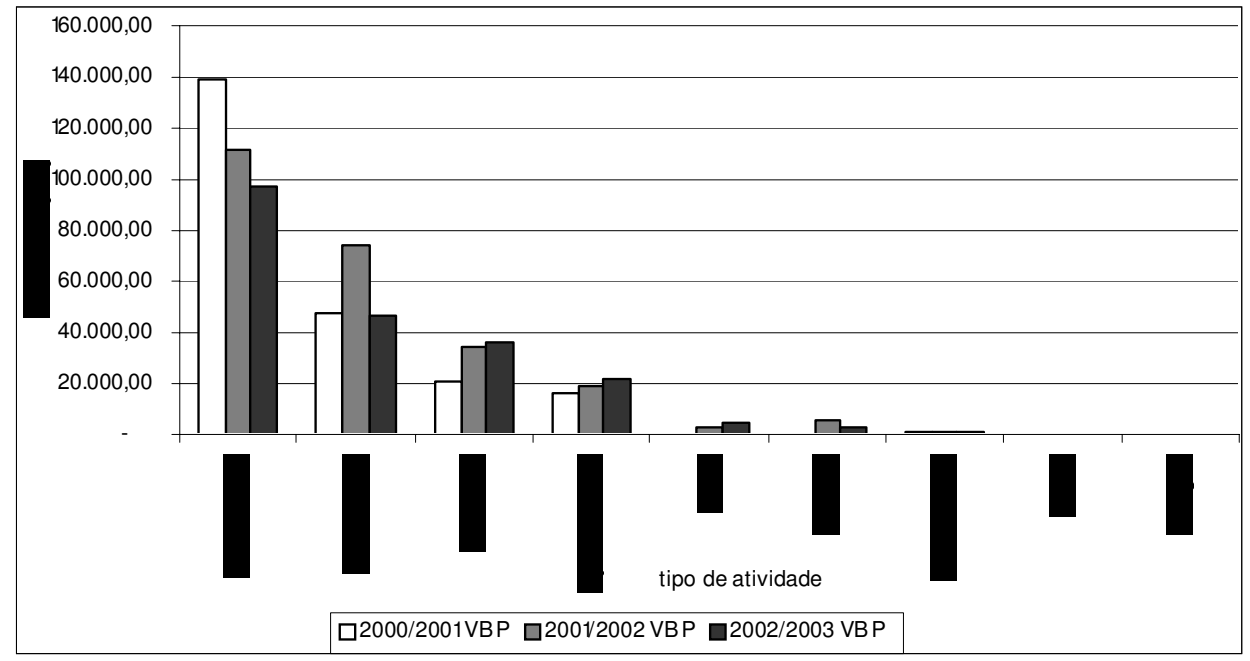

Figura 7: Evolução do Valor Bruto da Produção (VBP) dos 24 estabelecimentos familiares de Cumaru (valor atualizado R\$/ciclo). 
De um modo geral, há uma flutuação interanual nas receitas globais das atividades agropecuárias, com um crescimento significativo das receitas obtidas de terceiros ou de apoios e benefícios governamentais, como as aposentadorias, a bolsa-escola, a bolsa-alimentação, o valegás, o salário-maternidade. Porém, o valor bruto vendido (VBV), que representa os valores provenientes de atividades produtivas internas e externas aos estabelecimentos, apesar de apresentar um crescimento entre os ciclos de 2000/2001 e de 2001/2002, sofre uma pequena queda entre os ciclos de 2001/2002 e de 2002/2003, passando de R 201 393,57 para R\$ 213 559,06 e para R\$ 172 385,00, respectivamente. As culturas permanentes, que representavam $68,8 \%$ das vendas totais em 2000/2001, passaram a representar 51,3\% em 2001/2002 e 55,4\% em 2002/2003. As temporárias cresceram de 20,6\% para 30,9\%, sofrendo uma redução para $22,6 \%$ no terceiro ciclo. Os níveis de dependência das atividades externas na formação do VBP passaram de $16,9 \%$ para $22,5 \%$ entre o primeiro e o segundo ciclo e para $30,1 \%$ entre o segundo e o terceiro ciclo agrícola (Tabela 8).

Tabela 8: Variação do Valor Bruto da Produção (VBP) e do Valor Bruto das Vendas (VBV) nos 24 estabelecimentos familiares de Cumaru (valor atualizado em $\mathrm{R} \$$ /ciclo).

\begin{tabular}{|c|c|c|c|c|c|c|c|c|c|c|c|c|}
\hline \multirow{2}{*}{$\begin{array}{l}\text { Tipo de } \\
\text { atividade }\end{array}$} & \multicolumn{4}{|c|}{ 2000/2001 } & \multicolumn{4}{|c|}{ 2001/2002 } & \multicolumn{4}{|c|}{ 2002/2003 } \\
\hline & VBP & $\% \mathrm{VBP}$ & VBV & \% VBV & VBP & $\% \mathrm{VBP}$ & VBV & \% VBV & VBP & \% VBP & VBV & $\%$ VBV \\
\hline Permanente & $138.857,64$ & $61,9 \%$ & $138.568,39$ & $68,8 \%$ & 111.182,21 & $44,8 \%$ & $109.617,11$ & $51,3 \%$ & $96.703,00$ & $45,9 \%$ & $95.448,00$ & $55,4 \%$ \\
\hline emporário & $47.312,55$ & $21,1 \%$ & $41.429,60$ & $20,6 \%$ & $74.200,14$ & $29,9 \%$ & $66.077,91$ & $30,9 \%$ & $46.241,08$ & $22,0 \%$ & $38.936,00$ & 22,6\% \\
\hline Terciário & $20.823,76$ & $9,3 \%$ & $20.862,41$ & $10,4 \%$ & $33.883,31$ & $13,7 \%$ & $31.057,52$ & $14,5 \%$ & $36.233,00$ & $17,2 \%$ & $34.048,00$ & 19,8\% \\
\hline Aposenta & $16.052,74$ & 7,2\% & - & $0,0 \%$ & $19.069,80$ & $7,7 \%$ & - & $0,0 \%$ & $22.280,00$ & $10,6 \%$ & - & $0,0 \%$ \\
\hline Ajuda & - & $0,0 \%$ & - & $0,0 \%$ & 2.491,95 & $1,0 \%$ & 233,10 & $0,1 \%$ & $4.600,00$ & $2,2 \%$ & 290,00 & 0,2\% \\
\hline Pastoril & - & $0,0 \%$ & - & $0,0 \%$ & $6.060,60$ & $2,4 \%$ & $6.027,30$ & $2,8 \%$ & $3.300,00$ & $1,6 \%$ & $3.000,00$ & $\quad 1,7 \%$ \\
\hline Extrativismo & $1.008,70$ & $0,4 \%$ & 441,47 & $0,2 \%$ & 775,89 & $0,3 \%$ & 457,32 & ०,२\% & 954,40 & $0,5 \%$ & 613,00 & $\quad 0,4 \%$ \\
\hline Apoio & - & $0,0 \%$ & - & $0,0 \%$ & 266,40 & $0,1 \%$ & - & $0,0 \%$ & 270,00 & $0,1 \%$ & - & $-\quad 0,0 \%$ \\
\hline Criação & 144,10 & $0,1 \%$ & 91,70 & $0,0 \%$ & 88,80 & $0,0 \%$ & 88,80 & $0,0 \%$ & - & $0,0 \%$ & - & $0,0 \%$ \\
\hline Total & $224.199,49$ & $100,0 \%$ & $201.393,57$ & $100,0 \%$ & $248.019,09$ & $100,0 \%$ & $213.559,08$ & $100,0 \%$ & $210.581,48$ & $100,0 \%$ & $172.335,00$ & $100,0 \%$ \\
\hline
\end{tabular}

Fonte: Banco de dados do Projeto SHIFT (2003).

De um modo geral, a contribuição do maracujazeiro na formação do valor bruto da produção (VBP) tende a cair de 59,1\% em 2000/2001 para 36,3\% em 2001/2002, passando depois para 13,7\% no ciclo 2002/ 2003. A pimenta-do-reino, por sua vez, teve uma elevação de 2,8\% para $7,4 \%$ e $31,7 \%$ no mesmo período. A mandioca teve um crescimento de $7,5 \%$ para $10,8 \%$ entre os dois primeiros ciclos, estabilizando-se em 
10,6\% no terceiro ciclo. Entre as hortaliças, como o coentro, a couve, a alface, o cheiro-verde, a pimenta-doce, etc., observa-se uma flutuação interanual do VBP, com uma variação da importância relativa de cada cultura. Ao mesmo tempo, as receitas das atividades assalariadas, como colheita, capina, construção civil, ensino (professores), serviços (serventes e agentes de saúde), juntamente com as receitas de aposentadoria e de benefícios públicos, aumentaram sensivelmente nos últimos anos.

A crise da cultura do maracujazeiro traz sérias implicações para a sustentabilidade dos estabelecimentos familiares do Cumaru, afetando diretamente a renda familiar e as bases de funcionamento dos sistemas de produção estabelecidos na comunidade. Encontrar alternativas de uso dos meios de produção disponíveis para esse novo contexto é o dilema fundamental dos agricultores familiares do Cumaru. Substituir culturas, refazer as formas de gestão do solo, reordenar o uso do espaço de produção e da mão-de-obra familiar são os problemas fundamentais desses agricultores.

\subsection{CONSTITUIÇÃO DE NOVOS SISTEMAS DE PRODUÇÃO}

Em 1999, 67\% dos sistemas de produção que representavam as 24 famílias estudadas na comunidade de Cumaru eram baseados, principalmente, na cultura do maracujazeiro; o restante realizava os cultivos tradicionais do roçado e outras atividades extra-agrícolas. A partir de então, novos sistemas de produção têm se formado, com diferentes estratégias de mobilização e uso dos recursos de produção.

Um dos estabelecimentos (4\% do total) especializou-se na produção de hortaliças, empregando um grande número de componentes familiares jovens e concentrando esforços na inserção profissional em toda a cadeia de produção de hortaliças da região. Apesar de se caracterizar por uma alta carga de trabalho por ciclo agrícola, o uso do trabalho marginal familiar permite o aumento da eficiência do trabalho na formação da renda familiar e na remuneração do trabalho dos membros da família. O uso tradicional de corte e queima apenas funciona para a limpeza da área pela primeira vez, seguindo-se um ciclo de cultivo contínuo baseado em hortaliças por dois anos e a implantação de culturas semiperenes e perenes (Tabela 14).

Um segundo tipo de sistema de produção (21\% do total) apóia-se na manutenção do cultivo do maracujá e, por vezes, da pimenta-doreino, usando como estratégia o arrendamento e o cultivo do 
maracujazeiro em comunidades que não foram seriamente afetadas pela virose (doença que reduz a produção dessa cultura). Apesar de demandarem grandes investimentos na implantação das parcelas de maracujá e pimenta-do-reino, o uso de meios de transporte não é um fator restritivo destes sistemas de produção, com exceção das estacas e do arame para a implantação destas culturas.

O terceiro tipo de sistemas de produção (21\% do total dos casos) caracteriza-se pelo estado de crise que afeta a renda familiar, decorrente dos problemas da cultura do maracujá. Esses sistemas de produção apresentam disponibilidade de trabalho familiar (maior média de unidade de trabalho por estabelecimento) e um alto grau de pressão sobre a capoeira, com uma média de 43\% de área utilizada/ano. Em virtude da redução constante da renda familiar, são feitas roças extensas, visando a ampliação da produção de mandioca, como forma de complementação da renda.

O quarto tipo de sistemas de produção (13\% do total) também é remanescente dos sistemas baseados no maracujá. Como estratégia da reposição das perdas na renda familiar, esses sistemas de produção intensificam o trabalho familiar ou o uso do solo por meio da mecanização ou do uso continuado das parcelas. Apesar de representar a maior média de dias trabalhados por trabalhador (197 dias/UT), a remuneração do trabalho na agricultura é inferior à dos demais sistemas diversificados. A área reduzida para o cultivo é um fator importante de intensificação.

O quinto tipo de sistemas de produção, que corresponde a 38\% do total de estabelecimentos estudados, caracteriza-se pela forte participação de atividades externas ou pelas fontes de renda externas. Em geral, nos estabelecimentos que constituem esse tipo de sistema de produção, mais de 50\% das receitas provêm de atividades extraagrícolas. Esses sistemas também apresentaram perda de eficiência nas atividades agropecuárias, com uma redução sensível na remuneração do trabalho familiar por estabelecimento. O número de sacos de farinha produzidos, por exemplo, caiu de 26,3 para 17,3 sacos nos últimos três anos. Esse tipo de sistema foi o que mais cresceu nos últimos três anos, com um aumento de 50\% do total de novos estabelecimentos. Parte dos estabelecimentos da amostra apresenta remuneração do trabalho inferior ao salário mínimo do período.

O sexto e último tipo de sistema de produção (4\% do total) é formado pelos sem-terra, que realizam cultivos em áreas cedidas por outros agricultores ou vendem a mão-de-obra para outros agricultores da comunidade. A eficiência do trabalho familiar é muito baixa, 
representando aproximadamente $\mathrm{R} \$ 4,00 /$ dia trabalhado, além de ocupar apenas 170 dias ano/UT. A eficiência desse sistema de produção está diretamente relacionada ao funcionamento dos sistemas que cultivam o maracujá e a pimenta-do-reino, que demandam mais mão-de-obra durante os períodos de picos de colheita.

Em geral, a maioria desses sistemas de produção apresenta uma redução na renda agropecuária, acompanhada de um aumento da renda externa, que passa de 16\% para $48 \%$ entre 2000 e 2003. A queda da renda agropecuária é acompanhada também de uma queda na média da remuneração do trabalho familiar dos estabelecimentos, que cai de $\mathrm{R} \$ 16,58$ para $\mathrm{R} \$ 12,94$ em três anos de acompanhamento. Porém, de um modo geral, os estabelecimentos mais afetados pela crise do maracujá foram os que não conseguiram estabelecer cultivos perenes ou ampliar as rendas externas, como os do tipo 3. Para esses sistemas, a renda familiar reduziu-se de $\mathrm{R} \$ 14$ 507,00, no ciclo 2000/2001, para R $\$$ 10 638,00 no ciclo 2001/2002, caindo em seguida para $\mathrm{R} \$ 5735,00$ no ciclo 2002/2003. Do mesmo modo, a produtividade do trabalho familiar desses estabelecimentos passou de R \$ 17,06/dia, no ciclo 2000/2001, para $\mathrm{R} \$ 12,02 /$ dia no ciclo 2001/2002, caindo em seguida para $\mathrm{R} \$ 7,06 /$ dia no ciclo 2002/2003. Embora a renda familiar dos sistemas de produção dos tipos 4 e 5 não tenha sido afetada, a produtividade do trabalho desses estabelecimentos sofreu uma redução significativa nos três ciclos.

A origem principal da renda externa está nos serviços estatais voltados para a ajuda e a seguridade social rural, o que afeta ainda mais a eficiência das atividades agropecuárias nesses estabelecimentos familiares. Como já havia sido destacado em estudos desenvolvidos por Bonnal, De Reynal e Figueiredo (1994), sem uma leitura clara das influências sobre a produtividade do trabalho, a intervenção estatal gera um processo de redução dos efeitos globais na formação da produção e da renda familiar. A intervenção estatal, por meio das políticas de benefício social, parece ter ajudado a reduzir ainda mais o resultado global das atividades agropecuárias nesses estabelecimentos.

Além do mais, na maioria dos casos, a taxa de uso do solo é superior à capacidade de regeneração da fertilidade natural da capoeira, com as áreas utilizadas (AU) representando aproximadamente 50\% da superfície total $^{3}$, o que indica uma baixa disponibilidade de pousio. Em outras palavras, nem mesmo o tempo necessário de três a quatro anos de pousio está sendo respeitado pela maioria dessas famílias.

${ }^{3}$ Considerando-se também, no cálculo global das proporções, as áreas de igapó, definidas como reservas e fora dos ciclos de uso agrícola. A exclusão dessas áreas diminuiria ainda mais a disponibilidade de superfície proporcional cultivável. 
No contexto da crise dos estabelecimentos familiares locais, provocada pela redução do papel do maracujá na economia familiar e pela crise de fertilidade da capoeira, o projeto de aplicação da tecnologia de mulch constitui uma experimentação e uma inovação na agricultura, uma precondição para a introdução de tecnologias que favoreçam a gestão da fertilidade e da capacidade de geração de renda. De fato, a própria diversidade de condições é um fator determinante para a adoção dessa tecnologia. Dos 24 estabelecimentos estudados, apenas 6 apresentavam superfície disponível para gerir a fertilidade a médio prazo. Desses 6, apenas 4 apresentavam disponibilidade de trabalho para realizar atividades adicionais e 2 dispunham de recursos para realizar investimentos adicionais em insumos agrícolas complementares.

Dessa forma, a tecnologia de mulch aparece como uma das possibilidades de resolução dos problemas de fertilidade ambiental e de geração de renda para essas famílias, uma tecnologia que se insere no processo de transformação tecnológica em curso, como já demonstram os casos estudados.

\section{2 - INTENSIFICAÇÃO AGRÍCOLA E A TECNOLOGIA DE MULCH}

É importante destacar que a tecnologia de mulch destina-se, principalmente, a resolver os problemas de perda constante de fertilidade acumulada na capoeira, por meio do aumento da eficiência do pousio na recomposição da biomassa global do estabelecimento.
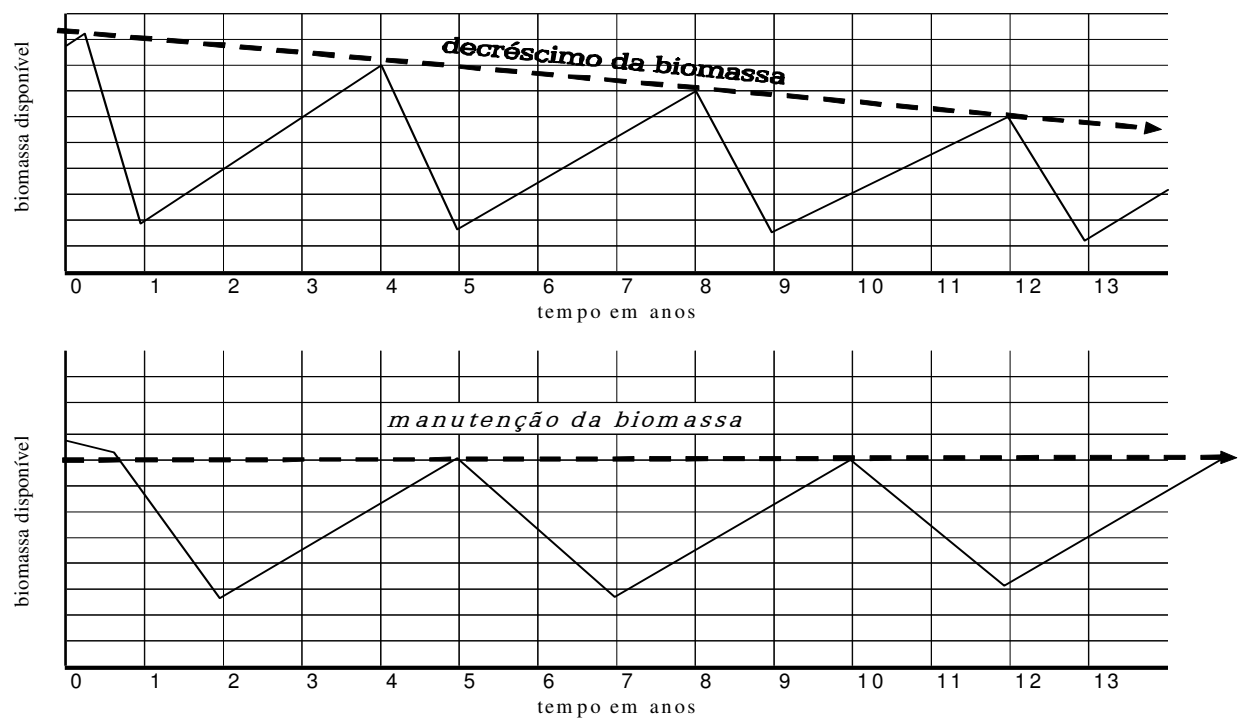

Figura 8: Esquema de mulch. 
A defesa da tecnologia de mulch apóia-se na tese de que existe uma crescente perda de biomassa nos ecossistemas da região bragantina, demonstrada na primeira parte deste documento, com base na amostra estudada. Por outro lado, ela funda-se na constatação de que a maior parte da atividade familiar concentra-se na produção do roçado.

As análises preliminares de 21 estabelecimentos da amostra apontam um crescimento da proporção de roças anuais e de cultivos perenes entre 2000 e 2003. A área de cultivo anual passou de 31\% para $45 \%$ da área cultivada média por estabelecimento. Apesar do crescimento recente, a área de roça não se apresenta como a maioria das áreas cultivadas por estabelecimento, como se imaginava. Juntas, culturas perenes e semiperenes somavam $61 \%$ da área média cultivada em 2000, mas, com a crise da cultura do maracujá, passam a representar $51 \%$, por causa de um leve crescimento das culturas perenes e da forte queda das semiperenes em 2003 (Tabela 9).

Tabela 9: Importância do roçado na proporção de áreas cultivadas por estabelecimento (amostra de 21 estabelecimentos).

\begin{tabular}{lrrrrrrrr}
\hline \multirow{2}{*}{ Culturas } & \multicolumn{3}{c}{ Quantidade/Ano } & \multicolumn{5}{c}{$\% /$ Ano } \\
\cline { 2 - 9 } & 2000 & 2001 & 2002 & 2003 & 2000 & 2001 & 2002 & 2003 \\
\hline Anuais & 19,36 & 22,79 & 26,39 & 28,19 & $31 \%$ & $35 \%$ & $41 \%$ & $45 \%$ \\
\hline Perenes & 19,32 & 22,19 & 22,65 & 23,71 & $31 \%$ & $34 \%$ & $36 \%$ & $38 \%$ \\
\hline Semiperenes & 19,06 & 14,23 & 13,61 & 8,06 & $30 \%$ & $22 \%$ & $21 \%$ & $13 \%$ \\
\hline Outras & 5,19 & 5,19 & 1,05 & 2,10 & $8 \%$ & $8 \%$ & $2 \%$ & $3 \%$ \\
\hline Total global & 62,93 & 64,40 & 63,70 & 62,06 & $100 \%$ & $100 \%$ & $100 \%$ & $100 \%$ \\
\hline
\end{tabular}

Fonte: Banco de dados do Projeto SHIFT.

Graças à análise do impacto da trituração, é possível avaliar o peso real dessa tecnologia na concretização dos efeitos globais de sustentabilidade técnica dos sistemas de produção. Quando se compara o resultado global das parcelas cultivadas com base no cultivo tradicional de corte e queima e o das estabelecidas com base na tecnologia de mulch, observa-se que as culti-vadas de modo tradicional consumiram 24,5\% do tempo total de trabalho familiar e geraram $27,7 \%$ da renda nos 24 estabelecimentos, enquanto as parcelas cultivadas com base na tecnologia de mulch (trituradas) absorveram $6,2 \%$ do trabalho e geraram 4,2\% da renda líquida. A eficiência econômica dos resultados produtivos dessas parcelas também não é a mesma: as parcelas queimadas geraram 
uma remuneração do trabalho familiar da ordem de $\mathrm{R} \$ 16,29$ por dia trabalhado, enquanto as trituradas remuneraram o trabalho familiar a $\mathrm{R} \$$ 8,52 dia/homem.

Tabela 10: Resultados globais da renda e da remuneração do trabalho familiar com e sem trituração da capoeira.

Fonte: Banco de dados do Projeto SHIFT.

Obs: Cálculo com base no período de fevereiro de 2001 a maio de 2002.

Uma análise detalhada permite, porém, constatar também uma forte diferenciação nos resultados econômicos por estabelecimento: enquanto alguns obtiveram um produto bruto anual da ordem de $32,2 \%$ com as parcelas cultivadas, outros conseguiram apenas 1,5\% do montante global do valor bruto da produção do estabelecimento.

Tabela 11: Valor bruto da produção do estabelecimento familiar e participação das parcelas trituradas.

Item

\begin{tabular}{|c|c|c|c|c|c|}
\hline Família & $\mathrm{VBP}$ & 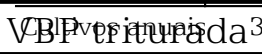 & $982,60 \operatorname{ta} 4,5 \%$ & $74.200,14$ & $29,9 \%$ \\
\hline 1 & $7.857,82$ & 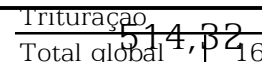 & $\frac{999,6,50,2 \%}{186,8,5180,0 \%}$ & $\begin{array}{r}12.046,44 \\
248.019,09\end{array}$ & $\begin{array}{r}4,9 \% \\
1000 \%\end{array}$ \\
\hline 10 & $13.542,50$ & $1.197,30$ & $8,8 \%$ & & \\
\hline 11 & $3.373,50$ & $1.085,50$ & $32,2 \%$ & & \\
\hline 13 & $22.970,00$ & 559,20 & $2,4 \%$ & & \\
\hline 14 & $13.302,55$ & 304,00 & $2,3 \%$ & & \\
\hline 15 & $9.569,50$ & 773,80 & $8,1 \%$ & & \\
\hline 16 & $10.385,00$ & 782,00 & $7,5 \%$ & & \\
\hline 2 & $7.676,00$ & 150,00 & $2,0 \%$ & & \\
\hline 20 & $8.950,10$ & 530,00 & $5,9 \%$ & & \\
\hline 21 & $7.888,00$ & 155,00 & $2,0 \%$ & & \\
\hline 22 & $5.202,00$ & 978,13 & $18,8 \%$ & & \\
\hline 4 & $9.049,10$ & $2.535,40$ & $28,0 \%$ & & \\
\hline 6 & $6.983,00$ & 770,00 & $11,0 \%$ & & \\
\hline 7 & $2.694,30$ & 338,00 & $12,5 \%$ & & \\
\hline 8 & $11.923,00$ & 180,00 & $1,5 \%$ & & \\
\hline Média & $9.424,42$ & 723,51 & $10,0 \%$ & & \\
\hline
\end{tabular}

Fonte: Banco de dados do Projeto SHIFT. 
Considerando-se um limite equivalente ao salário mínimo diário da época (SM) e o resultado obtido nas atividades produtivas cultivadas com a tecnologia de mulch (RW), percebe-se que apenas alguns casos conseguiram superar o limite de remuneração do trabalho nas parcelas trituradas (Figura 8).

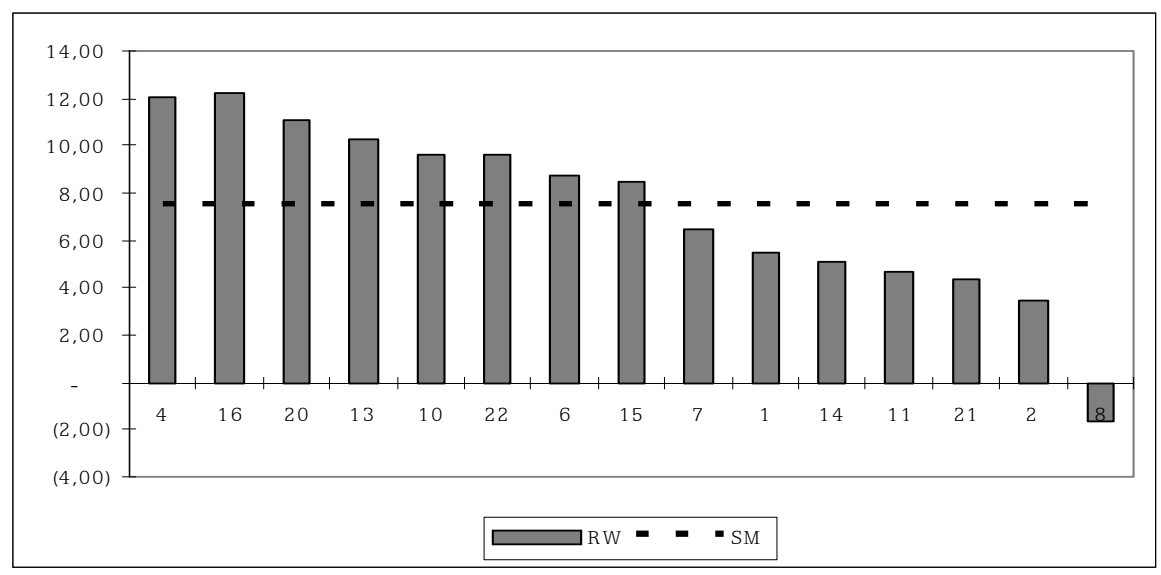

Figura 9: Remuneração do trabalho em relação ao valor médio do salário mínimo diário nas parcelas trituradas

A análise detalhada dessas parcelas demonstra claramente que os componentes de produção que mais contribuíram na obtenção da renda líquida e na remuneração do trabalho familiar foram as culturas do maracujá, do feijão-caupi e da mandioca (ver Tabela 12).

Tabela 12: Atividades produtivas e resultados econômicos por estabelecimento familiar na trituração

\begin{tabular}{c|l|r|r|r|r|r|r}
\hline NFamília & \multicolumn{1}{|c|}{ Cultura } & Área & \multicolumn{1}{c|}{ W } & \multicolumn{1}{c|}{ Custo } & \multicolumn{1}{c|}{ VBP } & \multicolumn{1}{c}{ RL } & RW \\
\hline 4 & Maracujá (AT) & 0,40 & 191,0 & 226,00 & $2.535,40$ & $2.309,40$ & 12,09 \\
16 & Feijão & 0,89 & 33,0 & 378,30 & 782,00 & 403,70 & 12,23 \\
20 & Mandioca/Milho/Feijão & 0,45 & 42,5 & 57,50 & 530,00 & 472,50 & 11,12 \\
13 & Mandioca/Milho/Feijão & 0,57 & 36,75 & 181,00 & 559,20 & 378,20 & 10,29 \\
10 & Feijão/Mandioca & 0,52 & 107,8 & 157,30 & $1.197,30$ & $1.040,00$ & 9,65 \\
22 & Mandioca/Milho/Feijão & 0,90 & 94,0 & 72,00 & 978,13 & 906,13 & 9,64 \\
6 & Mandioca/Feijão & 0,61 & 29,7 & 510,75 & 770,00 & 259,25 & 8,73 \\
15 & Arroz/Milho/Mandioca & 0,58 & 83,0 & 69,38 & 773,80 & 704,42 & 8,49 \\
7 & Mandioca/Milho/Feijão & 0,60 & 43,5 & 57,00 & 338,00 & 281,00 & 6,46 \\
1 & Feijão/Mandioca & 0,25 & 83,9 & 54,75 & 514,32 & 459,57 & 5,48 \\
14 & Feijão/Pimenta-doce & 0,32 & 41,00 & 96,00 & 304,00 & 208,00 & 5,07 \\
11 & Feijão/Mandioca & 0,61 & 207,0 & 117,75 & $1.085,50$ & 967,75 & 4,68 \\
21 & Mandioca/Feijão & 0,55 & 24,0 & 50,00 & 155,00 & 105,00 & 4,38 \\
2 & Feijão/Maxixe & 0,45 & 42,5 & 3,00 & 150,00 & 147,00 & 3,46 \\
8 & Mandioca & 0,15 & 24 & 220,00 & 180,00 & $(40,00)$ & $(1,67)$ \\
\hline Média/Estabelecimento & 0,5 & 72,2 & 150,05 & 723,51 & 573,46 & 7,34 \\
\hline
\end{tabular}

$\mathrm{W}=$ Trabalho, VBP $=$ Valor Bruto da Produção, $\mathrm{RL}=$ Renda líquida e RW = Remuneração do 
A eficiência média da tecnologia também precisa ser ponderada, uma vez que se encontra em processo de experimentação, que visa resolver problemas e efetuar ajustes tecnológicos básicos.

\subsection{IMPACTOS DA TECNOLOGIA DE MULCH SOBRE AS PRÁTICAS- TÉCNICAS DOS AGRICULTORES}

A introdução de uma nova tecnologia também tem efeitos de ordem prática no conjunto de atividades ou práticas-técnicas de um sistema produtivo do estabelecimento familiar. No caso específico da trituração, além dos efeitos diretos no processo de fertilização, por meio das cinzas ou de uma mudança microclimática nos solos cobertos pela biomassa triturada, supõe-se que os impactos da trituração afetem o uso de tecnologias de plantio (plantio manual ou com tico-tico) e o desenvolvimento da vegetação invasora, atingindo diretamente o processo de capina com enxada.

Comparando-se os impactos globais sobre o tempo de trabalho familiar aplicado nas parcelas cultivadas em roças de corte e queima e nas parcelas trituradas, observa-se que o trabalho familiar médio por estabelecimento foi de 118 homens dias/hectare/ano nas parcelas queimadas e de 90 homens dias/hectare/ano nas parcelas trituradas. Apesar do maior tempo de trabalho aplicado nas parcelas que sofreram queima, o fracasso de alguns cultivos impossibilitou a continuidade do trabalho nas atividades consecutivas, como a colheita do milho, da mandioca ou do feijão (Tabela 13).

Tabela 13: Trabalho global nas roças de corte e queima e nas parcelas cultivadas.

\begin{tabular}{l|r|r}
\hline \multicolumn{1}{c|}{ Discriminação } & \multicolumn{1}{c|}{ Roça } & \multicolumn{1}{c}{ Triturada } \\
\hline Area cultivada & 33,6 & 11,1 \\
Trabalho aplicado & $3.962,0$ & 999,0 \\
\hline Média (W/ha) & 117,9 & 90,3 \\
\hline
\end{tabular}

Quando se compara o impacto da trituração sobre o tempo de realização do plantio do feijão com a plantadeira tico-tico, observa-se que ele aumenta com o tempo de trituração, que, em geral, é bastante afetado pelo tamanho médio da biomassa aérea. Na prática, o acúmulo de biomassa impede a penetração da plantadeira, afetando assim a dinâmica do plantio do feijão e de outras culturas baseadas no plantio em cova (Figura 9). Desse modo, as parcelas que foram plantadas com 
tico-tico e que sofreram trituração consumiram mais tempo de trabalho quando o volume de biomassa triturada era maior, afetando a produtibilidade do trabalho da atividade. O tempo médio de trabalho no plantio do feijão variou entre 6,6 horas e 15,5 horas por hectare/homem.

O mesmo processo também afetou o plantio de mandioca, gerando um incremento do tempo de trabalho na medida em que o tempo de trituração da parcela era maior. Contudo, no caso da mandioca, o grau de correlação entre o tempo de trituração e o tempo de plantio foi maior, o que pode influir fortemente na eficiência dessa cultura, com um tempo médio de trabalho por hectare variando de 46 a 81 horas/homem.

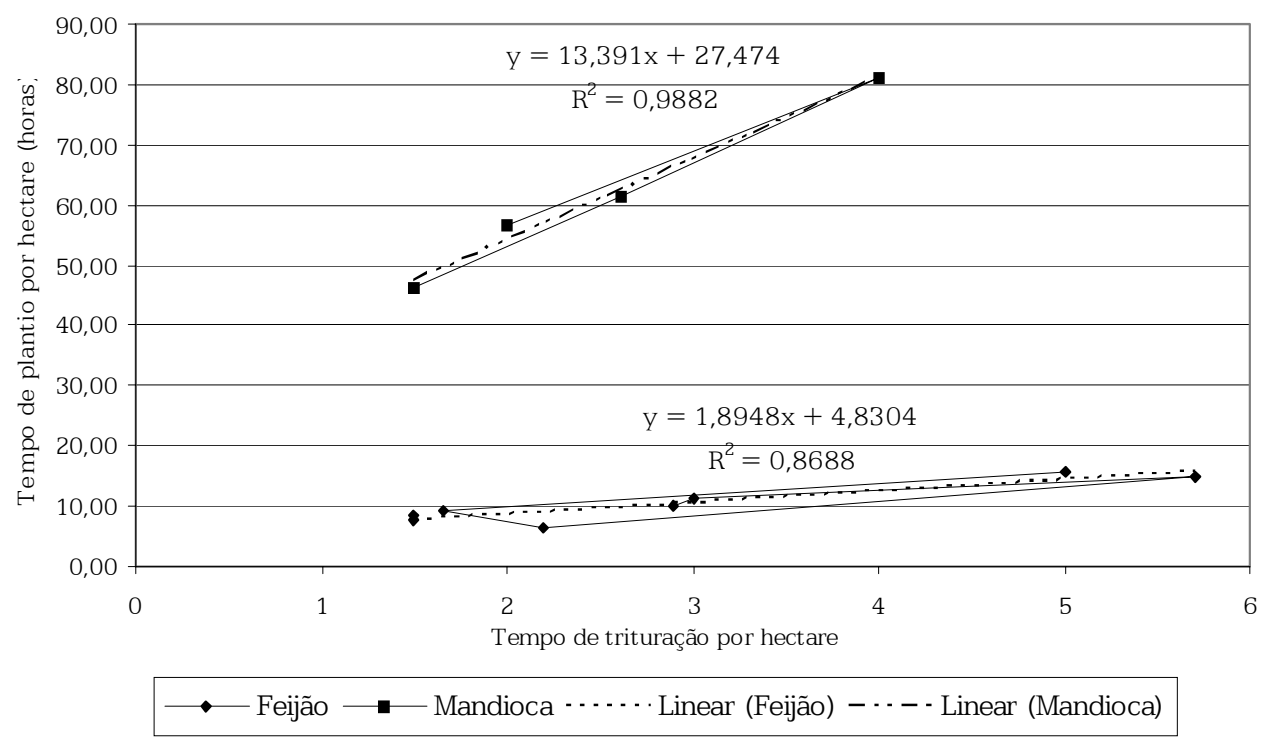

Figura 10: Relação entre o tempo de trituração e as práticas de plantio do feijão e da mandioca com a plantadeira tico-tico.

Os instrumentos e técnicas de plantio atuais, utilizados em combinação com as técnicas de trituração no cultivo do feijão e do maracujá, absorvem uma grande quantidade de trabalho no plantio. Por isso, deve-se conceber o uso de instrumentos alternativos, principalmente por causa das dificuldades de penetração no solo.

O tempo global da capina nas parcelas que sofreram queima e nas trituradas atingiu uma média de 25 dia/homem e 22 dias/homem, respectivamente. Apesar do menor resultado de trabalho médio na capina por hectare nas parcelas trituradas, as variações entre as duas modalidades foram muito pequenas, o que não permite destacar mudanças importantes no efeito da tecnologia sobre essa prática (Tabela 14). 
Tabela 14: Trabalho de capina* nos estabelecimentos que realizaram a queima das roças e o plantio após a trituração da capoeira.

\begin{tabular}{l|r|r}
\hline Discriminação & \multicolumn{1}{|c|}{ Roça } & \multicolumn{1}{c}{ Triturada } \\
\hline Area cultivada & 33,6 & 11,1 \\
Trabalho (dias) & 843,5 & 240,1 \\
\hline Média (W/ha) & 25,1 & 21,7 \\
\hline
\end{tabular}

* Considerando apenas as culturas tradicionais do roçado (mandioca, milho e feijão).

Porém, quando se compara o trabalho aplicado na capina da cultura da mandioca e na do feijão, observa-se que, com a tecnologia de trituração, houve uma redução do tempo médio trabalhado na capina de 48 dias para 21,5 dia/hectare/ano na cultura da mandioca. Na cultura do feijão, houve um aumento do tempo médio de trabalho de capina, que passou de 8,7 para 16,7 dias com o uso da trituração (Tabela 15).

Tabela 15: Trabalho de capina nas culturas da mandioca e do feijão nas roças de corte e queima e nas parcelas trituradas.

\begin{tabular}{l|r|r|r|r}
\hline \multirow{2}{*}{ Discriminação } & \multicolumn{2}{|c|}{ Cultura da mandioca } & \multicolumn{2}{c}{ Cultura do feijão } \\
\cline { 2 - 5 } & \multicolumn{1}{c|}{ Roça } & Triturada & \multicolumn{1}{c}{ Roça } & \multicolumn{1}{c}{ Triturada } \\
\hline Area cultivada & 14,6 & 4,1 & 8,1 & 5,8 \\
Trabalho (dias) & 707,0 & 88,5 & 70,0 & 97,8 \\
\hline Média (W/ha) & 48,3 & 21,5 & 8,7 & 16,7 \\
\hline
\end{tabular}

De forma abrangente, o trabalho na capina com o cultivo após a trituração foi positivo para a cultura da mandioca e negativo para a cultura do feijão, o que indica que a tecnologia de mulch pode ser menos eficiente para culturas de ciclos mais curtos que para as de ciclos anuais.

Um aspecto relevante e não mensurado foi notado nos trabalhos de campo por alguns agricultores. O grau de desenvolvimento das raízes das invasoras existentes no solo parece dificultar significativamente a colheita da mandioca, gerando possíveis perdas de raízes no arranquio. Um estudo adicional parece ser fundamental para a observação mais eficaz desse processo técnico.

De um modo global, considerando apenas as culturas anuais do roçado (milho, feijão e mandioca), a eficiência da produção nas parcelas cultivadas após a trituração foi inferior à das parcelas cultivadas após a queima: a produção média por hectare foi de $1475 \mathrm{~kg}$ e $8894 \mathrm{~kg}$, respectivamente. A cultura do milho tornou-se ineficaz nas parcelas cultivadas após a trituração, enquanto a do feijão apresentou uma produção média em torno de 500 kg/ha (Tabela 16). 
Tabela 16: Produção de milho, feijão e mandioca por hectare em parcelas cultivadas após a trituração e a queima da capoeira.

\begin{tabular}{l|r|r}
\hline Produto & Triturada & Queimada \\
\hline Mandioca & 12.034 & 273.992 \\
Feijão & 4.337 & 22.408 \\
Milho & - & 2.430 \\
\hline Produção total & 16.371 & 298.830 \\
\hline Área produtiva (ha) & 11 & 34 \\
\hline Produção/ha & 1.475 & 8.894 \\
\hline
\end{tabular}

O atraso na implantação das parcelas cultivadas parece ter influído significativamente nos resultados da produção do roçado, principalmente na cultura de milho, que apresenta maior exigência hídrica do que as demais culturas. Contudo, o acompanhamento agronômico não permitiu uma avaliação eficiente desse processo, o que reduz as possibilidades de conclusão sobre os efeitos climáticos e ambientais nessas parcelas. A realização de novas avaliações, com base em um monitoramento agronômico mais eficaz, torna-se necessária.

Por esse motivo também, observou-se uma grande variedade de combinações de culturas e de sucessões nas parcelas cultivadas, o que ocasionou restrições e dificuldades estatísticas de comparação das culturas implantadas.

Além desses fatores, há ainda a inclusão de novas práticas-técnicas no cultivo do roçado, que antes estava mais restrita aos cultivos de pimenta-do-reino ou às parcelas mecanizadas. A adubação e a calagem implicam um aumento do tempo de trabalho familiar no cultivo em capoeira triturada (4,2\% do total de dias) e dos insumos adicionados durante o primeiro ano de cultivo da capoeira.

\section{CONSIDERAÇÕES FINAIS}

Alguns aspectos básicos fundamentais precisam ser analisados antes de qualquer tipo de experiência desta natureza.

O primeiro refere-se à intervenção na forma de pesquisadesenvolvimento, que exige sempre um conhecimento amplo e qualificado da necessidade tecnológica do conjunto dos agricultores envolvidos e da destinação da tecnologia a esse conjunto. Notou-se que apenas uma parte das famílias selecionadas poderia apoiar-se na tecnologia como forma de recomposição da biomassa da capoeira, enquanto outras apresentavam biomassa em abundância e outras não mais a possuíam. 
Um acordo de base para a implantação de parcelas em meio real com processos técnicos muito bem definidos é necessário. Sem esse acordo, em geral, os agricultores tendem a diversificar o máximo as formas de uso do solo conforme as condições locais.

Outro aspecto diz respeito à necessária determinação de diagnósticos agronômicos para avaliar o efeito das práticas e do meio ambiente sobre o desenvolvimento das culturas estabelecidas. Isso permite definir com mais clareza as influências dos fatores tecnológicos sobre os resultados agronômicos das culturas implantadas.

Ficou evidente ainda que o principal problema tecnológico e econômico dos estabelecimentos da amostra concentrava-se na cultura do maracujazeiro. A doença tem reduzido significativamente a renda agrícola e a remuneração do trabalho das famílias da comunidade de Cumaru. Como conseqüência adicional, a ausência dessa cultura nos sistemas de produção tem gerado uma maior pressão sobre a capoeira, o que provoca uma redução da biomassa vegetal em virtude da necessidade de ampliação das roças anuais.

Esse processo tem resultado em uma menor participação da agricultura na formação da renda dessas famílias, seja pelo incremento do trabalho extra-agrícola das famílias mais pobres, seja pelas políticas de apoio governamental, como os programas de bolsa-escola, bolsaalimentação e outros.

Por sua vez, a experiência de intervenção não permitiu influir significativamente no conjunto dos estabelecimentos da amostra, tanto por ter sido estabelecida em pequena escala, como por ter tido efeito direto na geração de renda agrícola. Contudo, essa experiência possibilitou o estabelecimento de uma reserva de biomassa para a produção de lenha e madeira para o consumo doméstico por meio do enriquecimento. Esses produtos haviam desaparecido dos estabelecimentos por causa da pressão sobre a capoeira.

No que se refere ao impacto direto da tecnologia de mulch sobre o conjunto das práticas-técnicas, nota-se que o volume da biomassa triturada influi no tempo de plantio das culturas de mandioca e do milho, que se apóiam em instrumentos desenvolvidos para solos descobertos após a queima. O desenvolvimento de tecnologias adaptadas às novas condições precisa ser analisado, assim como o impacto dessas condições sobre a vida útil desses instrumentos em uso em parcelas sob trituração.

O trabalho de capina, que representa uma mudança ambiental importante, com a inclusão de uma cobertura morta e de obstáculos à 
penetração dos instrumentos, demonstrou ser importante para o desenvolvimento da cultura da mandioca e negativo para a cultura do feijão.

Do ponto de vista metodológico, um banco de dados de grande amplitude deve ser implantado com o acompanhamento periódico das famílias e das parcelas, para que seja possível a verificação imediata dos problemas possíveis, evitando-se, assim, a perda da qualidade das informações coletadas. 


\section{REFERÊNCIAS}

BASLÉ, M. Mise en perspective de l'institutionnalisme de quelques économistes allemands et américains. Économie Appliquée, Local, n. 4, p. 159-176, 1993.

BONNAL, P.; DE REYNAL, V.; FIGUEIREDO, Raul Batista de. Apostila de economia agrícola familiar. Belém: NEAF, 1994. 120 p.

COSTA, Francisco de Assis. Agricultura familiar em transformação na Amazônia: o caso de Capitão Poço e suas implicações na política e no planejamento agrícolas regionais. In: HOMMA, A. K. O. (Org.). Amazônia: meio ambiente e desenvolvimento agrícola. Brasília, DF: EMBRAPA, 1998. p. 277-319.

FIGUEIREDO, Raul Batista de. Capacidade de investimento na agricultura familiar na região de Marabá-PA, período de 1990 a 1996. 1998. 164 f. Dissertação (Mestrado em Agriculturas Familiares Amazônicas e Desenvolvimento. Sustentável) - Núcleo de Estudos Integrados sobre Agricultura Familiar, Centro de Ciências Agrárias, Universidade Federal do Pará, Belém, 1998.

Curso de capacitação sobre gestão de estabelecimentos familiares rurais. Santo Antonio de Tauá: NOVA AMAFRUTAS, 2004.

PROJETO SHIFT. (Env. 44). Pequenos produtores na Amazônia: interrelações entre ecossistema e o sistema social na utilização e proteção da floresta tropical. Belém: NAEA/ZEF, 2000. 45 p.

SIMÕES, Aquiles; FIGUEIREDO, Raul Batista de. Diagnóstico dos estabelecimentos familiares de Ourém. Ourém: NEAF/25 de Julho/ PRORENDA, 2001. 35 p. 